\title{
A comunidade imaginada a partir da fotografia: a obra do romeno Costică Acsinte (1897-1984)
}

\author{
Alice Rosim Sundfeld Di Tella Ferreira ${ }^{1}$ \\ DOI 10.20396/eha.vil4.3349
}

A discussão trazida para este artigo é produto de um recorte da pesquisa de iniciação científica (que contou com apoio do CNPq) e da monografia realizadas durante os últimos semestres. Nela trouxe um pouco desta experiência, que foi ter entrado em contato com lugares pouco explorados por mim, como a região dos Bálcãs e o aparato fotográfico.

O título "comunidade imaginada" escolhido para o artigo remete instantaneamente à obra de mesmo nome de Benedict Anderson, "Comunidades Imaginadas" ${ }^{2}$ Neste livro ele trata de como seria possível a criação e imaginação de uma comunidade de pessoas, que mesmo sem se conhecer, têm características em comum. Os elementos que as unem em torno de uma comunidade são culturais, símbolos nacionais, uma história em comum e uma mesma língua.

Para Anderson, uma língua em comum é o que faz com que as pessoas se comuniquem e se identifiquem como iguais. Com o surgimento da imprensa e o começo das publicações de livros em vernáculos específicos, foi-se direcionando o público leitor para obras de determinada região. Assim, os moradores de determinada região conseguiriam, através da leitura de tais textos, se identificar no meio daquelas palavras, ou seja, identificariam a mesma língua que falavam, os mesmos cenários que viviam e costumes e atitudes que eram os mesmos que praticavam.

Para Anderson, portanto, as publicações escritas de determinadas regiões possibilitariam a identificação entre os leitores daquele mesmo local, fazendo com que pudessem imaginar uma identidade própria - refletida nas obras - e, consequentemente, imaginar uma comunidade. A comunidade imaginada seria, então, representada através das publicações escritas.

Utilizei o texto de Walter Benjamin "A obra de arte na era de sua reprodutibilidade técnica"3 para acrescentar outro ângulo nesta análise. Neste artigo, Benjamin fala sobre a mudança da relação entre obra e espectador a partir da aceleração de tecnicidade nos processos de criação das obras de arte. Elas sempre foram reproduzidas, o que diferenciava a experiência do espectador quando

\footnotetext{
1 Graduada em História pela Universidade Estadual de Campinas (IFCH-UNICAMP).

2 ANDERSON, Benedict. Comunidades Imaginadas. Companhia das Letras, 2008.

3 BEN]AMIN, Walter. Aobra de artena era de sua reprodutibilidade técnica.1955. Disponível em:<https://edisciplinas.usp.br/pluginfile.php/1563569/ mod_resource/content/1/A\%20obra\%20de\%20arte\%20na\%20era\%20da\%20sua\%20reprodutibilidade\%20t\%C3\%A9cnica.pdf>. Acesso em: 06.08.2019.
} 
diante de um original e uma cópia, mas isto mudou conforme as obras de arte eram feitas a partir de processos técnicos, sendo a fotografia um grande exemplo de arte técnica.

As fotografias são infinitamente reprodutíveis, pois um único negativo pode ser a base para revelar inúmeras imagens. Desta forma, o original e a cópia passam a ser o mesmo objeto - cada foto é ao mesmo tempo cópia e original - e sua relação com o espectador passa a ser a mesma. A reprodução técnica leva à uma difusão e recepção coletivas das obras de arte, pois mais pessoas têm acesso às imagens de uma vez, diferente dos quadros que ficavam em um museu e só quem o visitasse poderia entrar em contato com determinada obra.

A partir destas duas teorias, de Anderson a respeito da comunidade imaginada e identidades e de Benjamin sobre as obras de arte sendo tecnicamente reproduzidas, penso sobre a possibilidade de se imaginar uma comunidade, ou seja, de se criar um sentimento de identificação entre as pessoas tendo fotografias como base. Acredito que as fotografias possam ser mais acessíveis do que os livros por serem mais facilmente disseminadas e também mais facilmente interpretadas uma vez que não é necessário que o espectador saiba ler para poder analisá-las, ainda mais em sociedades como a romena da primeira metade do século XX que-como apontarei mais adiante-, possuía um grande percentual de analfabetos.

As fotografias analisadas neste trabalho são de autoria do romeno Costică Acsinte (18971984), que iniciou a carreira como fotógrafo de guerra durante a Primeira Guerra Mundial (19141918). Depois do fim do conflito, ele se instalou na cidade de Slobozia, no distrito de lalomița (próxima de Bucareste, à leste) e abriu um estúdio fotográfico durante a década de 1920. O Foto Splendid Costică Acsinte, cenário de muitas das fotografias do romeno, foi o local no qual muitos moradores daquela cidade tiveram seus retratos tirados.

Acsinte era amplamente conhecido entre os cidadãos da cidade de Slobozia e região, e os fotografou em estúdio e fora dele, pelas ruas da cidade, em frente às casas de famílias ou durante celebrações. O fotógrafo não precisou fazer propagandas de seu trabalho em meios de comunicação, mesmo porque um jornal só foi criado em Slobozia depois que o estúdio Foto Splendid foi fechado em 1960. Assim, a divulgação de seu trabalho ocorria pelo fato de ele ter sido por muito tempo o único fotógrafo dessa cidade e região e também por causa da grande amplitude de retratados - era difícil alguém não ter sido fotografado por Acsinte ou não conhecer alguém que já o tivesse sido -, que possivelmente indicavam seu estúdio para seus conhecidos, além de provavelmente enviarem 
suas imagens para familiares e amigos como uma forma de lembrança ${ }^{4}$.

Fica evidente que ele foi realmente relevante para a história da cidade, já que em 2009 foi nomeado cidadão honorário de Slobozia e ainda hoje há uma discussão entre os cidadãos deste município para que se erga uma estátua em sua homenagem.

Quando o Foto Splendid foi inaugurado, a Primeira Guerra Mundial havia acabado fazia poucos anos e com o seu fim muitas mudanças ocorreram na Romênia. Os territórios da Bessarábia, Bucovina (pertencentes anteriormente ao Império Russo), do Banat e da Transilvânia (antes pertencentes ao Império Austro-Húngaro) foram anexados ao país em 1918 e 1919 e com isso sua extensão praticamente dobrou. A Romênia deste período, com a maior área nacional de sua história, ficou conhecida como Grande Romênia.

Estes territórios, que foram agregados ao país, eram historicamente reivindicados pelos romenos desde a formação do Estado nacional romeno em 1861 com a unificação entre os principados otomanos da Valáquia e Moldávia. Eram, desde o século XIX, tidos como territórios romenos pois tinham grande parte de população romena dentro de seus limites. Assim, quando foram anexados, a Romênia praticamente dobrou de tamanho, juntamente com sua população - e consequentemente também as minorias, que se tornaram mais presentes entre os romenos e passaram a reivindicar mais direitos e espaços.

Desta forma, acredito que o contexto romeno no entre guerras seja interessante para se analisar a questão de identidade nacional, pois com estas novas condições do país creio que a autoafirmação da população como romena era importante. A importância de afirmar a identidade romena e de manter aqueles novos territórios dentro do país deveriam ser pontos importantes da vida daquela população. Mesmo que Slobozia esteja localizada no antigo principado otomano da Valáquia, já fazendo parte da Romênia desde os seus primeiros dias, acredito que a importância do ato de se auto afirmar como parte daquele estado e como pertencente à cultural romena pelos cidadãos daquela cidade e região não era menos presente do que o que acontecia em territórios como os da Transilvânia.

Assim, elementos vistos em fotografias de Acsinte, ao meu ver, poderiam ser identificados por pessoas daquela região, neste caso, no período do entre guerras e serviriam para uma identificação entre espectador e retratados como iguais e pertencentes a uma mesma comunidade. Selecionei 7 fotografias para este trabalho que trazem alguns destes elementos que foram observados

4 Relembrando, de certa forma, os carte-de-visite, muito disseminados na França durante a segunda metade do século XIX. 
durante as análises das imagens.

Na Figura 01 vemos 6 mulheres fotografadas em estúdio, o que é possível deduzir a partir do cenário ao fundo (uma porta de vidro desenhada em uma espécie de pano), que aparece em várias outras fotos de Acsinte, e as fotos reveladas colocadas em um painel (atrás da menina à esquerda), que deviam ser fotografias para mostrar seu trabalho para quem viesse visitar o estúdio. Esta imagem não possui data (que na maioria das vezes aparece anotada pelo autor em forma de riscos no negativo ou escrita atrás de fotografias reveladas), mas como se sabe que seu suporte é o negativo de vidro, pode-se deduzir que a imagem foi feita entre os anos 1920 até cerca de 1955. Nesta imagem, a identificação mais óbvia que poderia ser feita entre espectadores e as pessoas representadas seriam as roupas das duas mulheres das pontas, que parecem ser roupas tradicionais romenas.

Já a Figura 02 traz o seu ano de origem riscado no negativo em placa de vidro: 1940. Nela aparecem inúmeras pessoas reunidas para saírem na foto, ao centro aparece o casal de noivos, sendo possível a identificação a partir da vestimenta da mulher e também das duas grandes velas que um dos convidados segura - estas aparecem em praticamente todos os outros casamentos registrados por Acsinte. Os registros de casamentos compõem grande parte do acervo do fotógrafo, o que nos faz pensar que ele possivelmente era contratado para fotografar tais eventos. São elementos deste tipo de celebração que aparecem na foto e em outras festas como estas que fazem com que seja possível a identificação entre romenos da época naquela região, que provavelmente já haviam participado de alguma cerimônia de casamento.

O velório registrado na Figura 03 é um dos inúmeros presentes no acervo de Acsinte. Ele possivelmente também era contratado para registrar este último momento dos familiares e amigos com seu ente querido, o que nos mostra dois rituais: o do velório e o de tirar fotografias durante este momento. Elementos que representam este ritual são identificáveis, como as coroas de flores colocadas na cena, as roupas escuras das pessoas e seu posicionamento em volta do caixão e a presença de religiosos (no canto esquerdo da fotografia). Um romeno daquela região e época conseguiria identificar tal imagem como sendo um velório, igual aos que ele também deveria participar.

O negativo da Figura 04 traz outras informações escritas além da data (26 de novembro de 1940), indicando também a autoria "FOTO-AXINTE5; SLOBOZIA-IALOMIȚA" e o tema de que trata "O regimento de 'Chirana'. Os militares representados nesta imagem parecem estar em algum momento de descanso e descontração, alguns fumando e todos posando para a foto. Militares apare-

5 Como às vezes seu sobrenome é grafado. 
[Figura 01]

Costică Acsinte. S.d.

Disponível em:<https://www.flickr.com/

photos/costicaacsinte/36693506875/in/album-72157687757413176/>. Acesso em: 22.12.2019.

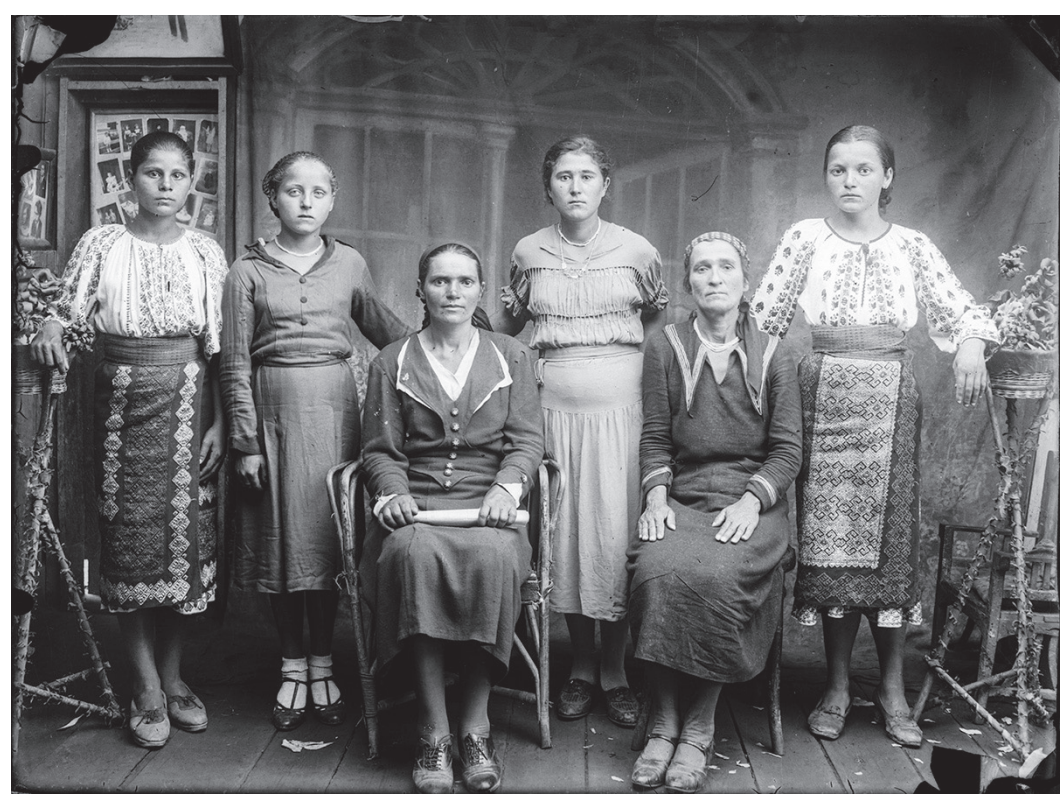

[Figura 02]

Costică Acsinte. 1940

Disponível em: <https://www.flickr.com/

photos/costicaacsinte/36170691640/in/album-72157684109283882/>. Acesso em: 22.12.2019.

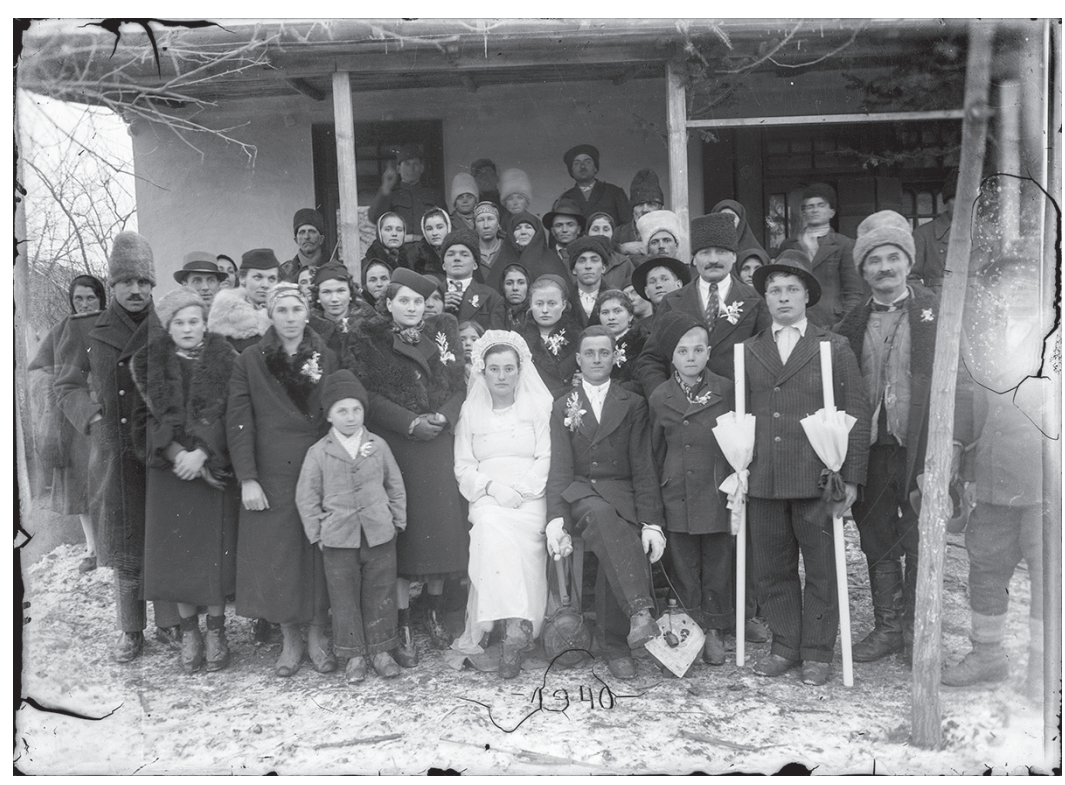

[Figura 03]

Costică Acsinte. S.d.

Disponível em: <https://www.flickr.com/

photos/costicaacsinte/30721593882/in/album-72157676896091115/>. Acesso em: 22.12.2019.

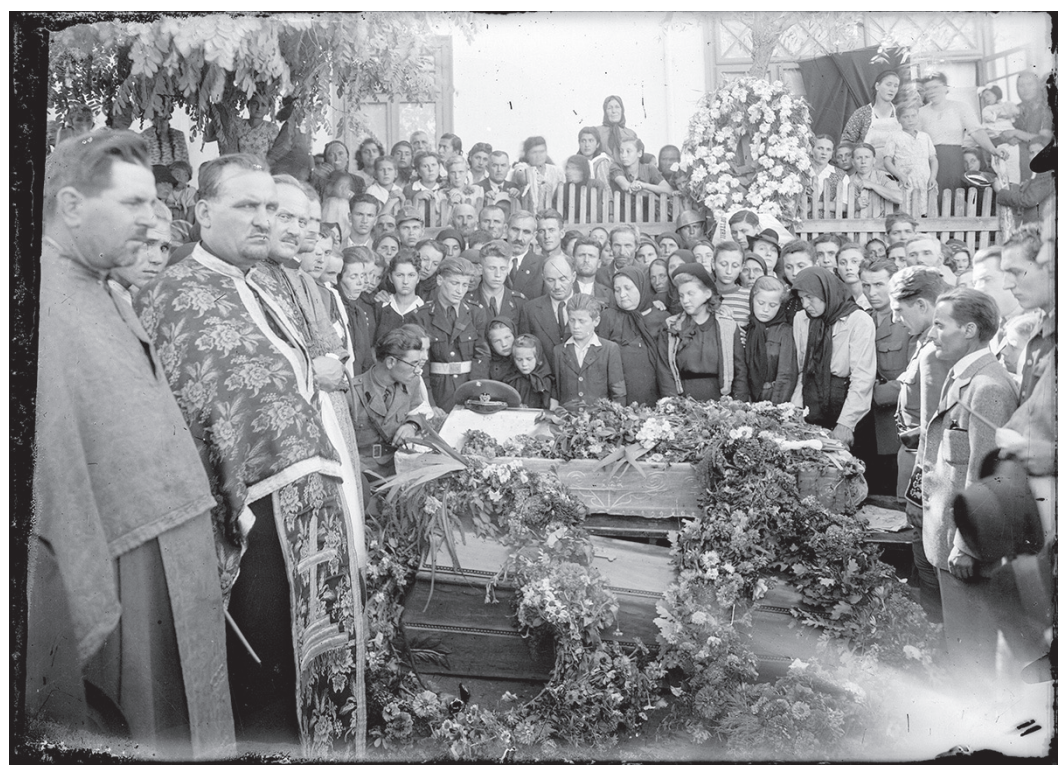


[Figura 04]

Costică Acsinte. 26 de novembro de 1940.

Disponível em: <https://www.flickr.com/ photos/costicaacsinte/18346911535/in/album-72157676896091115/>. Acesso em: 22.12.2019.

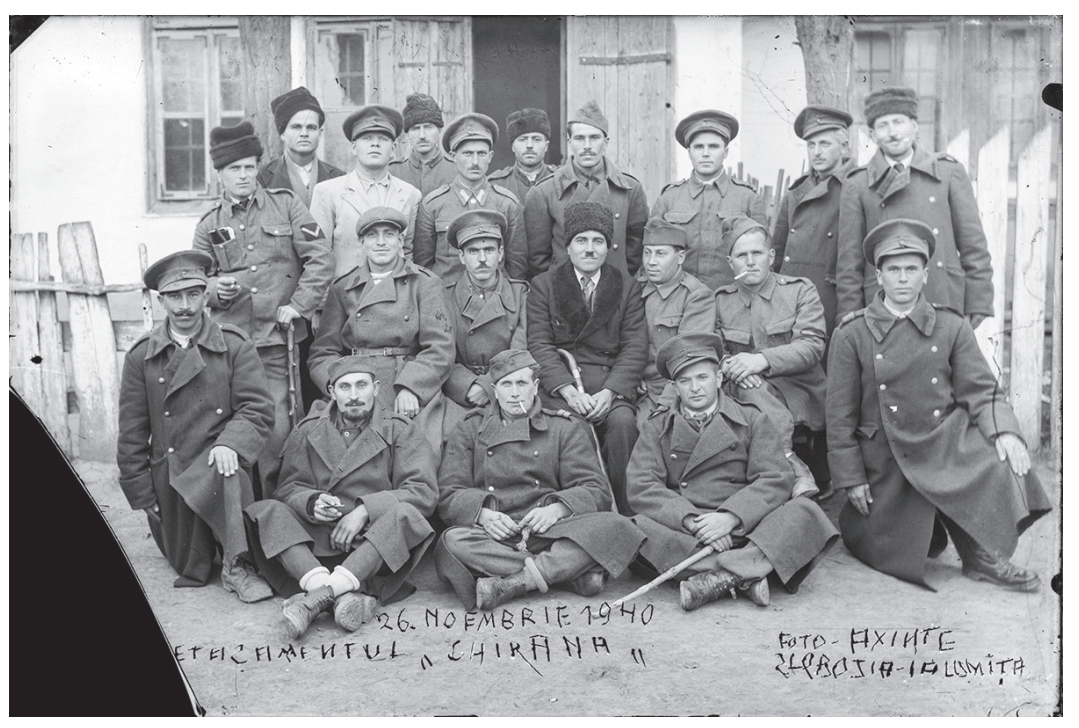

[Figura 05]

Costică Acsinte. S.d.

Disponível em: <https://www.flickr.com/ photos/costicaacsinte/37249269695/in/album-72157686647904023>. Acesso em: 22.12.2019.

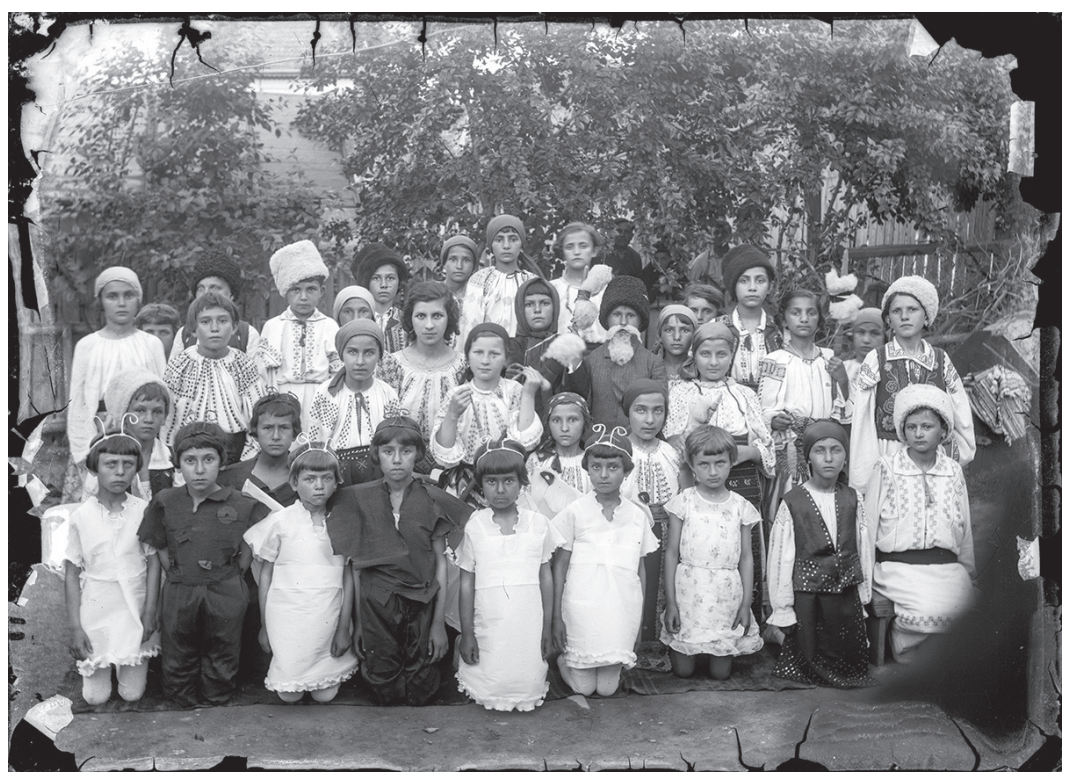

[Figura 06]

Costică Acsinte. S.d.

Disponível em: <https://www.flickr.com/ photos/costicaacsinte/36618908995/in/album-72157684194830172/>. Acesso em: 22.12.2019.

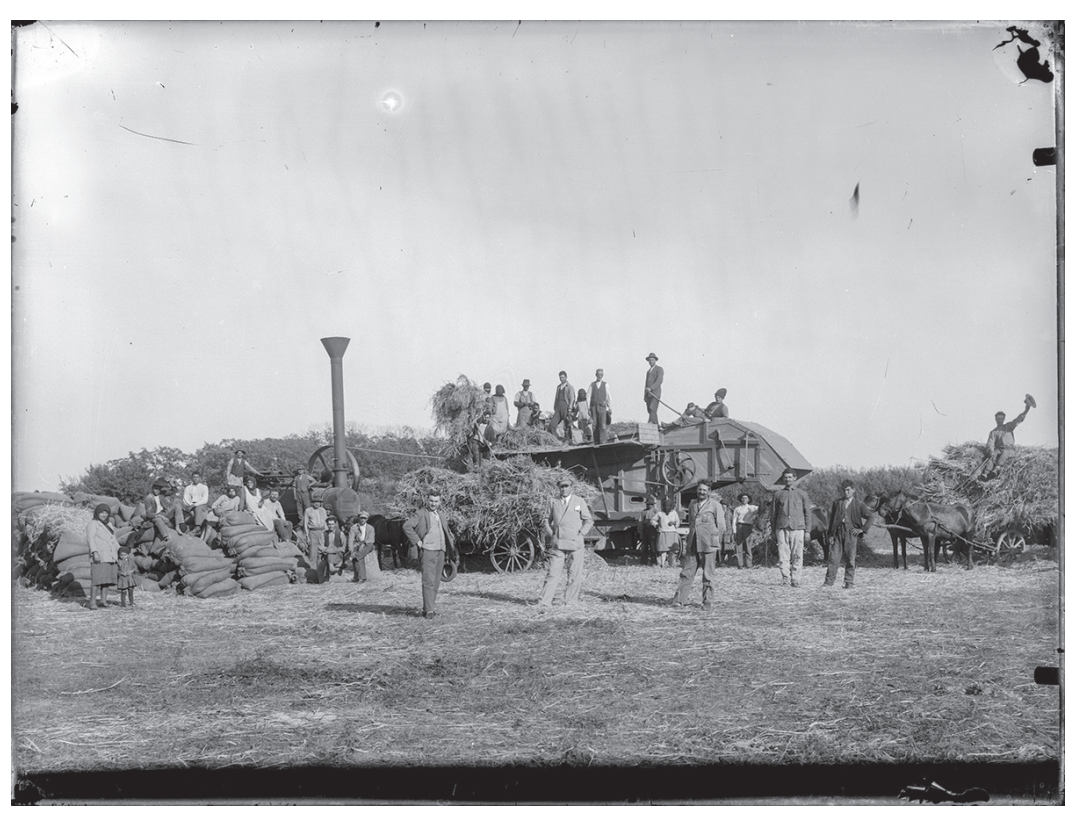


[Figura 07]

Costică Acsinte. 8 de setembro de 1940.

Disponível em: <https://www.flickr.com/ photos/costicaacsinte/35858702274/in/album-72157687757413176/>. Acesso em: 22.12.2019.

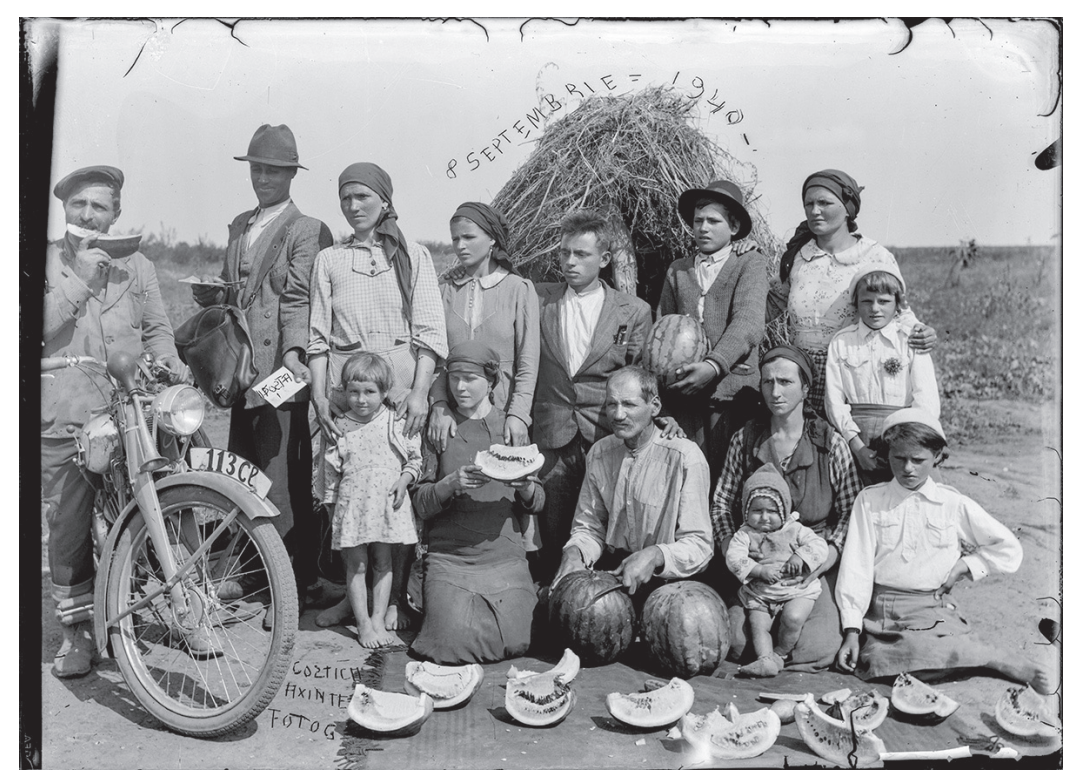

cem incessantemente em todo o acervo de Acsinte, em momentos de descontração, treinamento e entre a população civil - inclusive nas outras duas fotos anteriores militares aparecem entre os retratados. Acredito que a grande presença destes homens fardados em fotografias de Acsinte se deve ao período em que se encontram: no entre guerras, o país saindo da Primeira Cuerra Mundial, tentando se afirmar como verdadeiro proprietário dos territórios recém-anexados e já se encaminhando, como todo o continente, para a Segunda Guerra Mundial. Portanto, a presença militar no dia a dia da população romena do entre guerras devia ser al ta e constante.

As crianças que aparecem na Figura 05 parecem estar vestidas com roupas tradicionais romenas e também portam certos elementos fantasiosos, como barba e antenas de borboletas, o que pode nos fazer pensar do que se tratava o contexto, podendo ser uma apresentação infantil em alguma escola ou apresentação religiosa. Estes elementos, para algum cidadão romeno da época, poderiam ser muito claros e de fácil identificação, pois poderiam ter alguma relação com a história romena ou uma lenda do país.

Na Figura 06 vemos uma grande máquina agrícola cercada por vários homens e algumas mulheres e acompanhada também pelo o que parece ser a colheita feita e alguns sacos já cheios com o produto local. Na virada do século XIX para o XX, 80\% da população romena vivia no campo, o que foi pouco alterado na primeira metade do século $X X$, assim, muitas pessoas do distrito de lalomița poderiam se identificar com esta imagem, que mostra o modo de vida de muitas pessoas daquela região e país naquele período. Além disso, a máquina agrícola representa a modernização 
que estava sendo empregada desde o surgimento do Estado romeno nas áreas da agricultura, educação e industrialização, o que também fazia parte da rotina dos romenos de Slobozia, uma cidade bastante agrícola.

A Figura 07 traz consigo a data do registro (8 de setembro de 1940) e autoria "COSTIC ACSINTE FOTOS". Nela o fotógrafo parece ter atuado mais no posicionamento dos fotografados, que aparecem em frente a uma pilha de feno artisticamente posicionados. Os personagens da imagem parecem ser uma família que vende sua produção de melancias (posicionadas cortadas sobre um pano) para um comprador em cima de uma moto. Nesta foto aparecem vários elementos da sociedade romena daquela região e época, como o cenário rural e plano ao fundo, a produção de melancias e as vestimentas dos camponeses, por exemplo. Todos estes e outros itens poderiam ser observados e identificados entre os espectadores da fotografia.

Portanto, acredito que estes elementos que aparecem nas imagens de Acsinte possam ser vistos como de identificação entre cidadãos romenos da primeira metade do século XX, principalmente na cidade de Slobozia e sua região. Podendo criar, assim, uma identificação entre os seus espectadores como pertencentes a um mesmo grupo e comunidade, levando a imaginação de uma comunidade romena naqueles anos do entre guerras (centrada, neste caso, ao sul do país). Sendo possível desta forma pensar na criação de uma comunidade imaginada a partir de fotografias, que trariam em si os mesmos elementos culturais como as obras escritas (como defendido por Anderson) e poderiam ser mais facilmente disseminadas e analisadas entre a população local.

Referências Bibliográficas

ACSINTE, Costică. Archive. Disponível em: <https://www.flickr.com/photos/costicaacsinte/>. Acesso em: 06.08.2019. ANDERSON, Benedict. Comunidades Imaginadas. Companhia das Letras, 2008.

BENJAMIN, Walter. A obra de arte na era de sua reprodutibilidade técnica. 1955. Disponível em: <https://edisciplinas.usp. br/pluginfile.php/1563569/mod_resource/content/1/A\%20obra\%20de\%20arte\%20na\%20era\%20da\%20sua\%20 reprodutibilidade\%20t\%C3\%A9cnica.pdf>. Acesso em: 06.08.2019.

IACOB, Gheorghe. Romanians During the Emergence of Nation-States (1859-1918). In: POP, Ioan-Aurel; BOLOVAN, Ioan. History of Romania: Compendium. Cluj-Napoca: Romanian Academy, 2009.

KOSSOY, Boris. Fotografia e História. 2. ed. rev. São Paulo: Ateliê Editorial, 2001.

SĂLĂGEAN, Marcela. Romania between 1919 and 1947. In. POP, loan-Aurel; BOLOVAN, Ioan. History of Romania: Compendium. Cluj-Napoca: Romanian Academy, 2009. 